\title{
THE APPLICATIONS OF GIS FOR DEVELOPMENT SOME CHOOSING AREAS
}

\author{
Baylon M Angelica ${ }^{1}$, Panaitescu M \& Panaitescu F V ${ }^{2}$ \\ ${ }^{1}$ Maritime Academy of Asia and the Pacific, Mariveles Bataan, Philippines, e-mail address:ambaylon@maap.edu.ph \\ ${ }^{2}$ Constanta Maritime University, Constanta, Romania, e-mail address:mariana.panaitescu@cmu-edu.eu, \\ viorel.panaitescu@cmu-edu.eu
}

\begin{abstract}
This paper introduces Geographic Information System and its applications using datasets and innovative for research, extension services and development. Case study with GIS datasets is available for the Catanduanes Island. This application is good and efficient and will be recommended for actions in building GIS capability of human resources and for an environmentally sustainable and socio-economically Catanduanes support. GIS technology serves for the holistic development of different areas, in our case, for Catanduanes Island.
\end{abstract}

Key words : GIS, catalyst, research, extension, holistic development, island.

\section{INTRODUCTION}

If one is not sure where Catanduanes is, its relative position in Asia may be verified in Google Earth. Its geographic coordinate is at approximately $13^{0}-47^{\prime}$ North Latitude and at $124^{\circ}-26^{\prime}$ East Longitude (Figure 1). The island is about $40 \mathrm{~km}$ wide and $60 \mathrm{~km}$ long, situated in the eastern seaboard of the Bicol Region in Central Philippines [1].

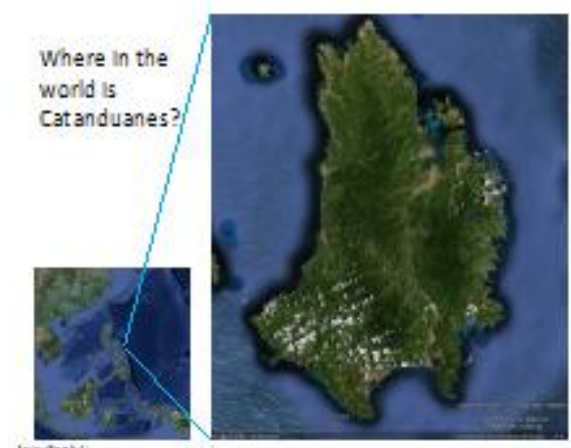

Figure 1 Catanduanes location [1]

The mission of the Province of Catanduanes is holistic. It is similar to that of many other provinces. Pursuing the mission equally requires a holistic approach, looking from the macro level down to micro level of doing things (Figure 2). A versatile technique that can help fulfill this mission with greater success is through the use of GIS.

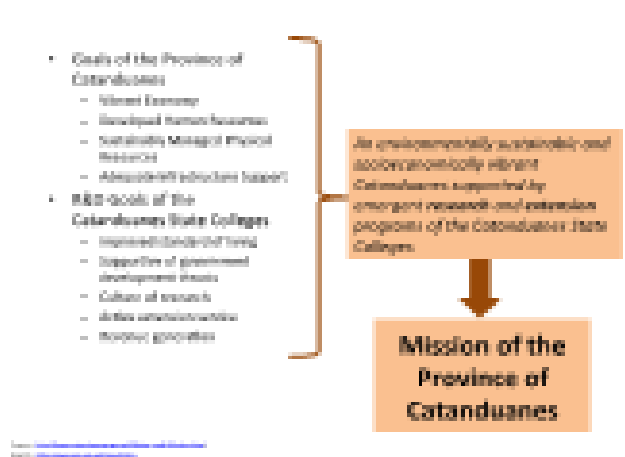

Figure 2. The mission of the province of Catanduanes [2]

The Province of Catanduanes aims for a vibrant economy, developed human resources, sustainably managed physical resources and an adequate Infrastructure Support [2]. On the other hand, the R\&D Goals of the Catanduanes State Colleges are for improved standard of living, supportive of government development thrusts, culture of research, active extension service, and revenue generation [3].

Now where GIS does comes in? How can GIS help in fulfilling the MISSION of Catanduanes? What is GIS? How can Catanduanes benefit from it? This paper answers these questions. Based on degree of applicability, this is a basic (fundamental or pure) type of research which is driven by the researcher's curiosity or interest in scientific questions. The main motivation is to 
expand man's knowledge, not to create or invent something. Based on approach or strategy, this is a grounded theory qualitative research that investigates the quality of relationships, activities, situations or materials wherein the researcher attempts to generate a theory that is grounded in data systematically gathered and analyzed. Hence this study utilized a basic grounded theory qualitative research using the following methods of data collection: internet search, literature search, documentary and content analysis with almost one year of intellectual email query (weekends or evenings) to a GIS specialist (Dr Alejandro Tongco from Oklahoma State University in USA) and marine biodiversity expert (Dr Jimmy Magasca from Catanduanes State Colleges in Virac Catanduanes Philippines). This is also based on the understanding of the researcher (GIS aspirant) having trained on GIS by the GIS expert Dr Alejandro Tongco as mentor during his visit in the Philippines as an invited trainer by MAAP. As part of MAAP and the PAEPI extension services program, GIS with software were shared and conducted to different interested groups as co-sponsors namely : Philippine Navy (former N8 Head Capt Sean Anthony Villa), the Province of Bataan at the Bataan Capitol (former Governor and Mayor Enrique Garcia), the Bataan Peninsula State University ( former President Dr Delfin Magpantay) and the Maritime Academy of Asia and the Pacific ( President VAdm Eduardo Ma R Santos, AFP ( Ret)). The researcher also facilitated the GIS training of MAAP interested students (MRESC and PAEPI members) on three Saturdays at the MAAP campus .

The National Conference on Water and Biodiversity and $3^{\text {rd }}$ Biodiversity Meeting (BIOME3) with theme "Water + diversity $=$ food + life $\ldots .$. " is a challenge to all .

Thinking beyond the above mathematical Biome 3 equation, the theme reminds everyone of responsibilities on this world so that future generations can still enjoy this planet earth that will be left behind.

Mathematically, the BIOME3 equation is incorrect. Transposing one variable from the right term to the left term doesn't make any sense. Certainly, the validity of the mathematical BIOME3 equation is not what Dr Aurora Araojo, the BIOME3 Organizing Chair and her BIOME3 Scientific Committee Team (Dr Jimmy Masagca, Prof Estrella Tribiana and Dr Teresita Avila) and colleagues form Catanduanes State University are trying to convey, rather, there are some metaphorical meanings to this BIOME3 equation. One of its definition is provided by this paper. It is believed that in order for "water + biodiversity" to result to "food + life", the BIOME3 equation needs a CATALYST. Hence, a new Biome 3 equation is proposed.

Water + diversity + GIS $($ Catalyst $)=$ food + life.....
GIS can be that CATALYST and can be shown in several ways through the various applications of GIS for Catanduanes, which shall be analyzed and interpreted in this paper on various illustrations.

\section{DISSCUTIONS AND RESULTS}

\section{$2.1 \quad$ GIS definition:}

Geographic Information Systems (GIS) (4) is a computerized analytical tool that processes geographic data and produces information that helps in making intelligent decisions. These are valuable to planners, administrators, educators, researchers, environmentalists, social scientists, institutional researchers, students, analysts, strategists, and policy makers. It is still evolving since its inception about 40 years ago.

\subsection{GIS , a Convergence of Several Disciplines:}

GIS is a new paradigm, a new way of thinking (Figure $3)$.

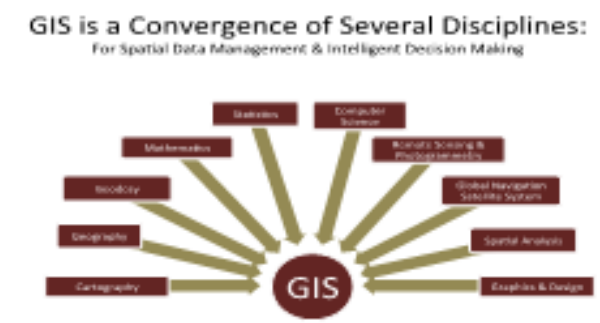

Figure 3. GIS , a Convergence of Several Discipline [4]

GIS is combination of several disciplines including, but not limited to, the following: Geography, Cartography, Geodesy, Mathematics, Statistics, Computer Science, Remote Sensing, Global Navigation Satellite System, Spatial Analysis, and Graphics \& Design, that are used in varying degrees to solve specific problems. GIS analysts must be generalists and must have high level of familiarity of several of these disciplines including his/her own professional background.

\subsection{GIS Applications by Discipline:}

Whatever field of specialization or disciplines, GIS can be applied to it. Some of the headings and subheadings below (particularly those underlined) in relation to the BIOME3 conference may be applicable to Catanduanes Province. 
Agriculture (Agricultural Economics, Agricultural Engineering Agronomy, Farm and Ranch Management, Pest Management and Veterinary Science); Architecture (City, Community, and Regional Planning, Landscape Architecture, Urban and Environmental Design); Business ( Banking and Financial Service Business Administration, Decision Support Systems, Economic and Management Research , Asset and Facilities Management, Marketing ,Media and Press, Operations Research, Real Estate Management and Retail); Defense, Security, and Intelligence ( Defense and Force Health Protection, Enterprise GIS , Geospatial Intelligence (GEOINT), Installations and Environment, Military Operations); Education (Campus / Multi-campus Management, Continuing and Distance Education, Educational Management and Administration, Elementary and High School, Institutional Research, Extension Planning, Vocational and Technical Education, Alumni Management, GIS Science \& Technology Curriculum Development, Research, Theses, \& Dissertations); Engineering (Aerospace Engineering, Chemical Engineering, Civil and Sanitary Engineering, Computer Engineering, Electrical Engineering ,Environmental Engineering, Geomantic / Geodetic Engineering / Surveying, Industrial Engineering, Mechanical Engineering , Mining Engineering); Government (National, Regional, Provincial, Local, Economic Development, Elections, Land Administration, Public Works, Urban and Regional Planning ); Law ( Real Estate , Jurisdictional Law); Libraries \& Museums (Government Documents, Map and Imagery Collections); Mapping and Charting (Aeronautical , Cartographic Publishing , Nautical , Spatial Data Infrastructure);Natural Resource Management (Conservation. Environmental Management, Fisheries, Forestry, Parks and $\underline{\text { Recreation, Petroleum, Range Management. Wildlife }}$ Management and Water Resources Management); Natural Sciences (Biostatistics, Botany, Conservation Biology, Entomology, Marine Biology, Zoology, Ecology, Environmental Science, Oceanography and Coastal Studies and Soil Science); Physical Sciences (Applied Physics, Climate Change, Computer Science, Geology, Geosciences, Earth Science, Geographic Information Sciences, Geochemistry , Hydrology, Paleontology , Quaternary Research , Seismology Research , Meteorology and Climatology); Public Health and Medicine (Environmental Health, Epidemiology, Hospitals and Health Systems, Managed Care, Public Health); Public Safety (Computer-Aided Dispatch, Criminal Justice, Criminology, Emergency/Disaster Management , Homeland Security, Law Enforcement, Fire and Rescue, Emergency Medical Services); Social Sciences (Area and Ethnic Studies, Anthropology and
Archaeology, Communications and Journalism, Economics, Geography, Historic Preservation International Studies, Political Science, Public Administration, Psychology, Sociology, Demography ; Travel and Tourism); Transportation (Aviation, Highways, Logistics, Railways, Ports and Maritime and Public Transit); Utilities and Communications (Electric, Gas, Location-Based Services, Pipeline .Telecommunications, Water/Wastewater)(5)

These are only partial list. Almost all disciplines can benefit from GIS. GIS has almost unlimited applications in many disciplines. As Roger Dangermond (founder of the ESRI, the maker of ArcGIS) has said, "The applicability of GIS is limited only by the imagination of those who use it."

As GIS is applicable to any disciplines, hence, GIS maybe used for Government, business, and research on environmental resource analysis, land use planning, locational analysis, Tax appraisal, utility and infrastructure planning, Real estate analysis, marketing and demographic analysis, habitat studies, and archaeological analysis; for Natural resources management like wildlife habitat, wild and scenic rivers, recreation resources, floodplains, wetlands; agricultural lands, aquifers, forests.; for Facilities management like locating underground pipes and cables; Balancing loads in electrical networks; planning facility maintenance, tracking energy use; for Land management like zoning and subdivision planning, land acquisition; Environmental impact policy, water quality management and Maintenance of ownership.; for Street-networks like location analysis, site selection; and development of evacuation plans.

\section{$2.4 \quad$ The GIS process}

The GIS process is made up of several components called inputs (spatial and non-spatial data, GIS software, Computer hardware, manpower and methods and processes). These data are processed (collected, recorded and manipulated/, stored, managed and retrieved, analyzed and modeled, displayed). The System produces useful information (which may be recycled) to produce specifically desired information (Figure 40 [5]. 
GIS datasets to be chosen are dependent on the

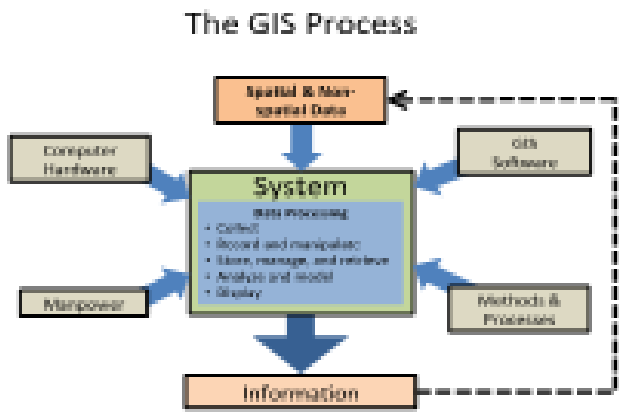

Figure 4. The components of GIS process [5]

organization, then its name can be written only once.

The font for the name of the organization is Times New Roman 10.

\subsection{Data input to GIS}

The GIS system needs data to be processed into useful information. Examples of input data are the following: digital maps, GPS readings, remotely-sensed imagery, tabular data, field survey data, digital products, texts etc (Figure 5)[6].

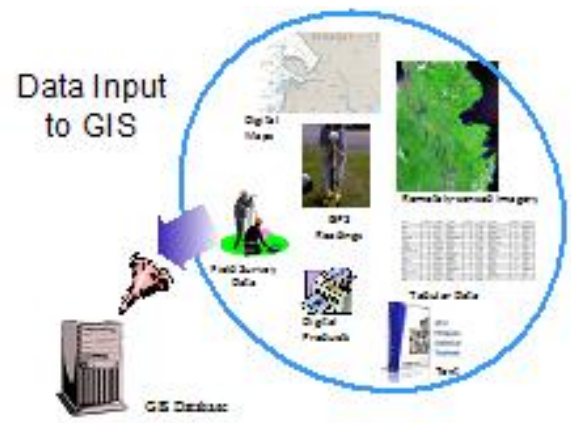

Figure 5. Data input to GIS [6]

The titles of sections and subsections will be aligned left and numbered consequently.

Terms that describe GIS have been repeatedly cited for emphasis and not for redundancy. This is done purposely to embed the concept of GIS in people's consciousness. GIS is a new paradigm - a new way of thinking. To some, if not to many of view, GIS may have a steep learning curve as illustrated by various data layers (land cover, structure, boundaries, hydrography, geographic names, transportation, elevation and orthoimagery.

The GIS project objective dictates the combination of datasets to collect.

\section{$2.5 \quad$ GIS datasets}

You can add or remove, zoom in or out, at will using GIS software. Each dataset contains an attribute table. 
Raster datasets may not readily show an attribute table, but they can be processed to produce attribute information.

Location is the key word in GIS. Without "Location" component, GIS is of no use.

Having common characteristics, almost all problems have a locational component. Problems involve people, location of people, things in those locations, events and phenomena in that location, and relationships of these components. These components and their relationships lend well to scientific GIS analysis and thus intelligent decisions. Hence, a challenge for Catanduanes

\subsection{Benefits for Catanduanes in using GIS}

Certainly, the use of GIS in the Province of Catanduanes would result to: Better Decision Making (Better decisions about location whether in research or development work and common examples include evacuation planning, conservation, natural resource extraction, school facilities management, etc. ) Making the right decisions about a location is critical to the success of an organization or project, e.g. in local governance, management of academic institutions, etc; Improved Communication (GIS-based maps and visualizations greatly assist in understanding situations and in chronicling. ) GIS results are a type of medium that improve communication between different project teams, departments, offices, professional fields, and the public.; Better Record Management (Maintains authoritative records about the status and change of geographic events and also Easy query and retrieval of spatial data that are centrally managed) Geographic records gives comprehensive transaction support and reporting.They are a valuable aid for fulfilling government and accreditation requirements.;Managing Geographically (Essential to understanding: what is happening - and what will happen - in a particular geographic location). Problem in understanding is necessary to make the correct prescription for action. Managing geographically is a new approach to management - taking into account the inherent geographic or spatial nature of things. The Overall Result: is increased efficiency and cost savings. [6]

\section{METHOD AND RESEARCH}

\subsection{Available Base GIS Data for Catanduanes}

To download free data, visit the website www.philgis.org [7] which is made available especially to GIS users of the Philippines. The following data maybe use for GIS-based research and development activities:
Province, Towns, and Barangays for use in population and demographic studies, student distribution studies, etc;

- Elevation data: DEM (digital elevation model, 30-m resolution) for use in delineation of protected areas, road construction planning, watershed delineation, river volume forecasting, etc ;

- Landsat ETM+ with 3 multi-spectral bands (30-m resolution) and panchromatic band (1-m resolution) for use in land-use and landcover studies, calculation of vegetative coverage, coastal resource management, etc.

- Bathymetry: 1-km resolution for use in marine studies, e.g. delineation of marine sanctuaries and protected areas and

- Rainfall for use in studies on climate change, erosion,flood disaster mitigation, etc.

\subsection{Selected GIS Applications/Uses for CatanduanesTables}

Form the BIOEME3 theme; some applications of GIS that are applicable to Catanduanes have been identified. Basic function of GIS is for mapping [8]. GIS may be applied for the social sciences; for campus facilities management; for assessing land cover and coastal resource; for protected area development; for disaster preparedness; for flooding simulation; for bird conservation ; and for navigation and marine resource management .

There are countless other GIS applications. But these cited examples are in relation with the conference BIOME3 theme and is believed, are most needed for the province and its higher educational institutions.

\subsection{Use of GIS for mapping}

Mapping is just one many basic uses of a GIS.

The first (1st) map at the top-left is the boundary map of Catanduanes Island (Figure 8-1). The second (2nd) map is that of Catanduanes and its municipalities (Figure 82 ). The third (3rd) map displays the municipalities applied with coloring scheme and labels (Figure 8-3). The fourth (4th) map displays the municipalities overlayed with barangay boundaries with labeling (Figura 8-4). These maps or part thereof are valuable in many phases of the GIS project: from planning to implementation to analysis to reporting to evaluation (Google Earth view of the Catanduanes State Colleges campus, Virac Campus, Taken 2010). 


\section{Journal of Marine technology and Environment Year 2021, Vol.I}

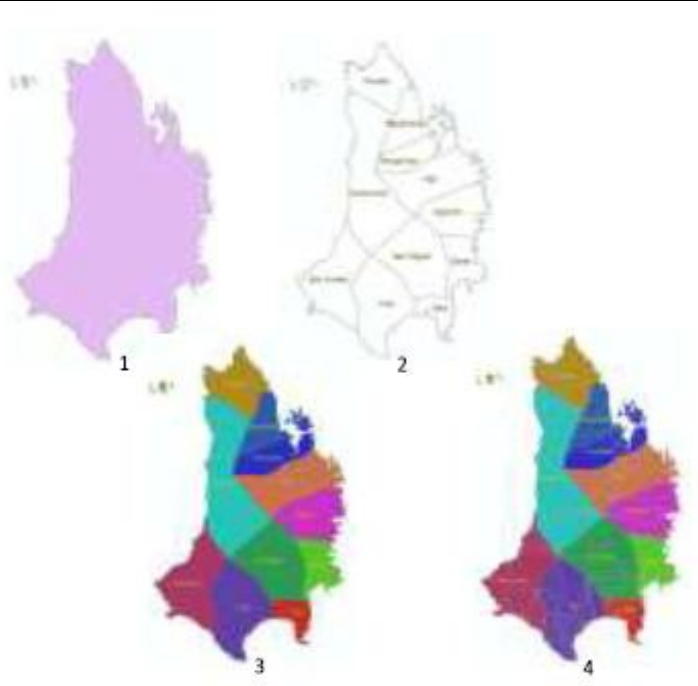

Figure 8 GIS for mapping

\subsection{Use of GIS for social sciences}

Focusing on one municipality in Catanduanes - the Municipality of Bato (Figure 9). Initially, color and labeling may be applied for its barangays.

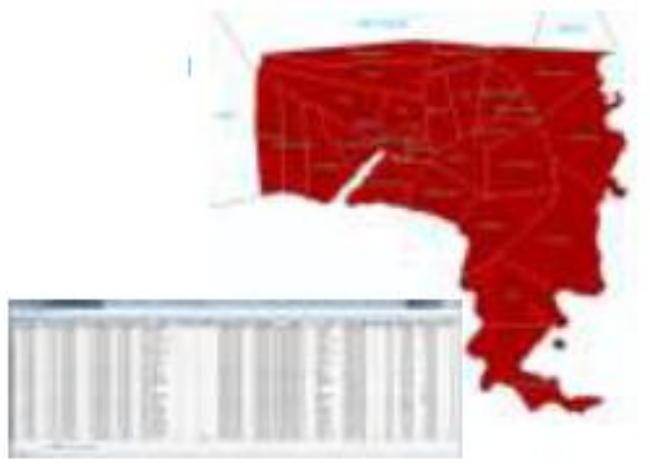

Figure 9 GIS for social sciences

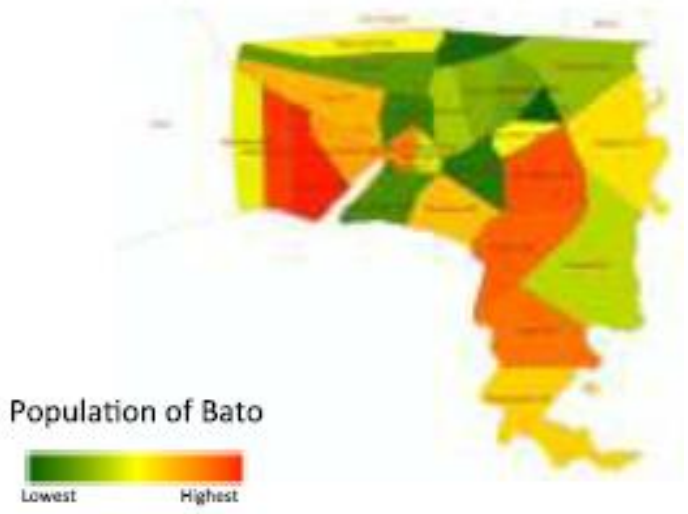

Figure 10 The Bato dataset

The Bato dataset contains a population field for the different barangays (Figure 10). The 2007 population of
Bato is 18,738 distributed over 4,582 hectares. Basic statistics such as sum, mean, and median can be calculated instantly using GIS software. The illustration above also labeled the population value per barangay. In this case, the highest is Bgy Cabugao with 2888 inhabitants and the lowest is Bgy Santa Isabel with 123 people. The picture obviously can give clues to politicians which barangays to prioritize their campaigns. (If the number of voters are included in the table, it could also be mapped and thus show a much better support for political planners.) DOH and DSWD personnel, as well as CSC researchers, can also be guided which barangays to focus their outreach programs.

A better measure of population is population density (i.e. number of people per unit area) this illustration shows the density distribution of barangays in Bato, in number of people per hectare (Figure 11). Red area (Bgy Ilawod) is the densest; green area (i.e. Bgys Buenavista, Cagraray, and Carorian) is the least dense. We can assume that Bgy Ilawod is the heart of Bato municipality. Again, the illustration can guide govt agencies, as well as HEIs, in planning for social and economic programs in the barangays. GIS analysts and planners may want to know why the eastern barangays are least dense. One might ask: What are the reasons behind it? Is it because of climatic conditions, agriculture, or other reasons? People may quickly guess for the reasons.

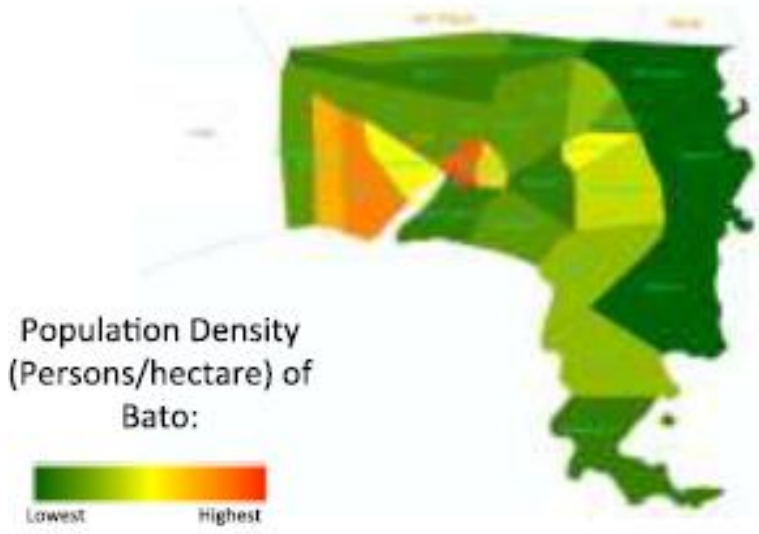

Figure 11 Population density of Bato

However, answers without supporting data or information are almost hearsay. The GIS analyst can help you find concrete evidence by overlaying several datasets, e.g. climate or rainfall, land cover, soils, 
diseases, and other datasets in order to come up with objective analysis to justify the implementation of development programs.

\subsection{Use of GIS for campus facilities management}

This a close-up view of the campus of the Catanduanes State Colleges displayed by Google Earth (Figure 12) [9].

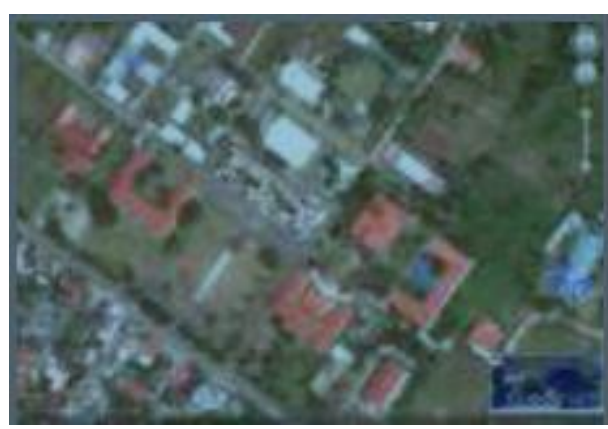

Figure 12 the campus of the Catanduanes State Colleges by Google Earth

One can see the building roofs and thus the footprints. Fortunately for GIS people, GIS datasets can be derived by digitizing (i.e., tracing a point, line, or polygon) the building footprints. To do this, we can convert the Google Earth KML file into a GIS shapefile, which can be done by most GIS software. Building footprints can also be scanned or digitized from building plans and then georeferenced (i.e. tagged to real-world coordinates). Most GIS software can do this conversion and georeferencing. Furthermore, room division lines may be traced for each building footprint. The resulting attribute table - which initially is empty - can then be populated with data such as number and specs of computers and other equipment, office furniture and fixtures, number of personnel, etc. Once the data are stored in a central database, the CSC President Dr Minerva I. Morales or a researcher can quickly query, retrieve,process, or print information about a certain room or all rooms in the campus and their assets. The ease in retrieving this data is valuable also to government such as CHED and TESDA, and accreditation groups, which are interested about such information. Similar process can be done to collect and manage data about the natural resources and other physical facilities of the campus such as water, sewer, telephone, and electrical lines; monuments; benches; trees; and others.

\subsection{Close-up of Virac area: Overlay of Landsat} imagery (CA year 2000), roads, and municipal boundaries

Roads and streets (yellow line), town boundary (white line) overlayed on Landsat imagery (Figure 13).

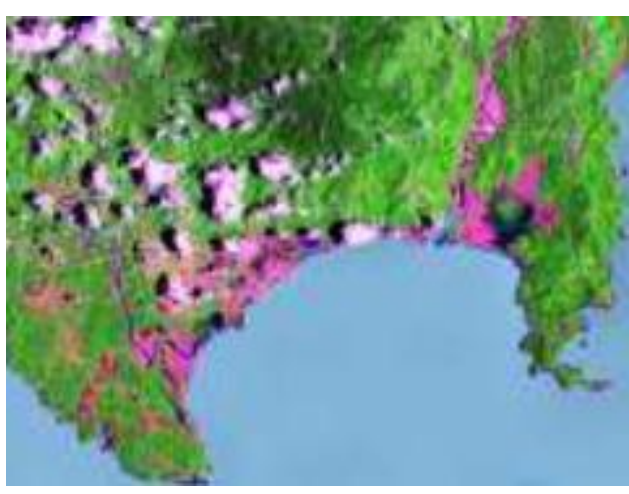

Figure 13 The Overlay of Landsat Virac imagery

Note again the cotton-like features of clouds. The dark areas left of the clouds are the clouds' shadows. The pink areas are urban or developed areas. The dark blue areas are water bodies such as rivers, fishponds, or cleared mangrove areas.

These have to be "ground-truth"to validate their presence.

\subsection{Use of GIS For Assessing Land Cover and Coastal Resource}

Here's a colored rendition of the Catanduanes terrain near Virac (Figure 14). Maps may present a good visual view of the landscape.

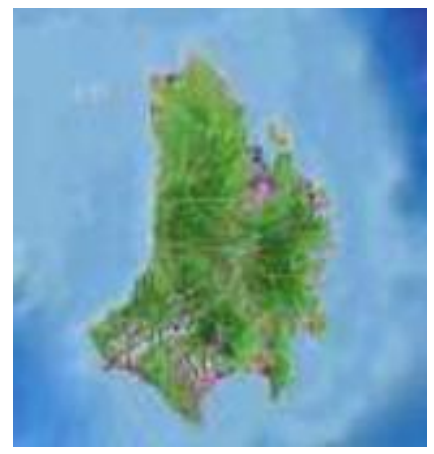

Figure 14 The Catanduanes terrain near Virac

But how useful is this to your GIS study? GIS is much more than just creating beautiful maps. Using the elevation map, you can delineate the certain elevations at certain location to be designated as protected areas.

Overlaying this with the Landsat image and barangay boundaries can give better information about land cover viz-a-viz selection of protected area and elevation, which is valuable for environmentalists and biodiversity specialists. Also, you can delineate the watershed(s) of the rivers that feed into Virac poblacion. 
This task is useful if you want to project the flooding that might occur in the city, the number of people affected, houses and building most probably flooded or destroyed, etc. Note that data layers can be added or removed at will with the click of a mouse. But first you have added this data to the GIS and make the necessary processing steps to display them nicely as you would want it.

\section{$3.8 \quad$ Use of GIS for protected area development}

This is an overlay of several GIS datasets: Administrative boundaries of towns and barangays overlaid on Landsat satellite imagery which in turn is overlaid on bathymetry (Figure 15). Land use / land cover is depicted by the Landsat image in various colors, e.g. dark green stands for forest cover, light green means thin forest cover or farm lands, red color is urban populated areas or absence of vegetation. The white cotton-like features are clouds. The dark areas beside the clouds are cloud shadows. From this map, planners can assess the extent of a particular land cover or land use, which barangays still have forests, which barangays have manmade structures such as fishponds, etc. GIS is about describing and analyzing the spatial relationships of the various data layers present in the map. The map also shows the variation in ocean depth depicted by graduated blue color.

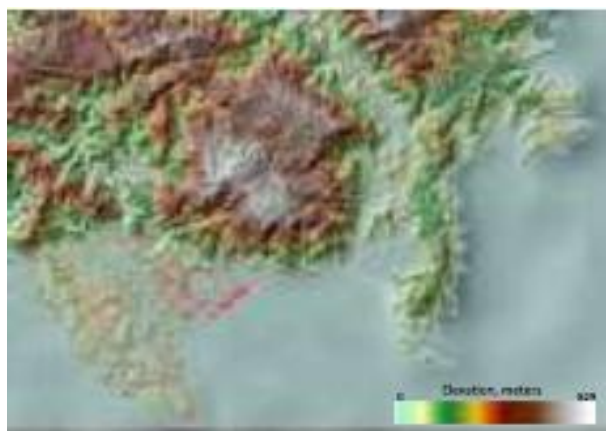

Figure 15 GIS for protected area development

The Landsat and bathymetry data used for this map are of low resolution and thus for approximation only. For critical studies, high-resolution imagery is needed to give detailed output.

\subsection{Use of GIS for disaster prepasredness}

GIS mapping and analysis is very important in dealing with disaster preparedness and mitigation. Several data layers are used here: provincial, municipal, and barangay boundaries as well as roads, overlaid on digital elevation model (Figure 16).

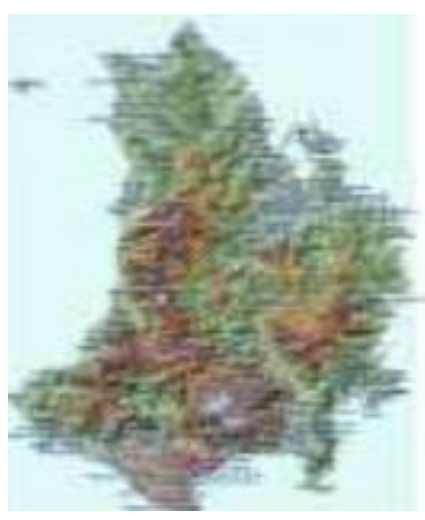

Figure 16 GIS for disaster preparedness

Which coastal barangays do you think would receive the most devastating hit if a tsunami occurs somewhere in the Philippine Trench?

It's Mother Nature's will, that Catanduanes is situated along the typhoon path. (God has positive reasons for making it so, which only few of us may be aware of.) Nothing can be done about it, but we can cushion the destructive effects of natural calamities if we make the necessary mitigating measures. Basically, GIS can help produce the maps that can simulate typhoon path, its strength, and the population that may be affected. People can be warned about areas that may be prone to landslides or flooding.

Let's think of climate change. How many of the coastal communities do you think will be submerged and how much? How will the rise in sea level affect the coastal communities of Catanduanes? Which barangays are most vulnerable? How many people will be affected? These are issues that can be better-addressed using GISengaged research by CSC and other institutions in Catanduanes.

On the questions why floods occur. These are some of the causes: Climate change ; Big waves; Continuous rainfall; Swollen rivers; Tsunamis; High tide; Man-made structures, negligence, indifference and Combination of the above. Climate change (high temperature) can cause water volume expansion, raising the sea level. To look at a simulation of coastal flooding, let's focus at some municipalities in northern Catanduanes.

3.10 View of Panganiban and Viga Municipalities, Northern Catanduanes, derived from Digital Elevation Model Data

This is what it may look like during normal days. Note the elevation legend at the lower right corner, ranging from a light blue ( 0 meter) to dark red to white (829 meters)(Figure 17). 


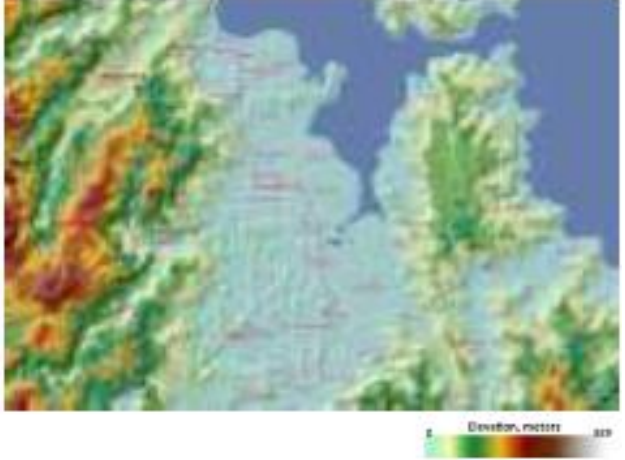

Figure 17 View of Panganiban and Viga Municipalities, Northern Catanduanes

Note the municipal and barangay boundaries, and the relative locations of the hills and mountains within the barangays.

\subsubsection{Flooding Simulation: 5-meter water level rise}

This is a simulation of coastal flooding when sea level rises to 5 meters. Note the flooding extent in the coastal barangays (Figure 18). Note also that pockets of water bodies inland have started to appear. Although flooding may appear small on the map, the actual flooded areas can be larger. The map shows which barangays to warn before a actual floods occur. Based on the simulation the number of people affected can also be estimated. How is the map made?

The map is an overlay of several GIS datasets, namely:

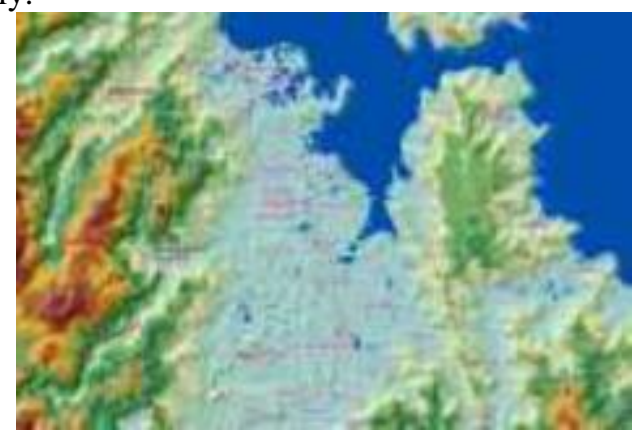

Figure 18 Flooding simulation-5 meter water level rise

DEM (digital elevation model) - elevation values were categorized and represented with graduated colors; Municipal and barangay boundaries (white line) this is to determine the relative location of flooding in the barangays and

Roads (red line) - this is also added to visualize which portions are flooded. This is important to know for emergency evacuation purposes. Other layers may be added such as churches, cemeteries, government buildings, etc.

\subsubsection{Flooding Simulation: 10-meter water level rise}

Now, this is getting scary. You can see which barangays are submerged (Figure 19).

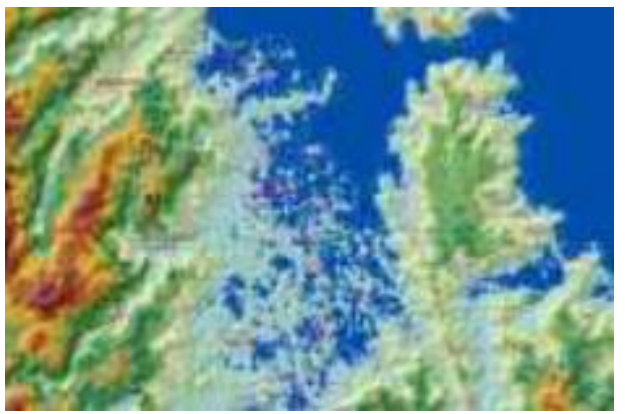

Figure 19 Flooding simulation-10 meter water level rise

Is there someone from the audience coming from any of these barangays or towns? Some of you may think your town or barangay is not affected because it's not shown on this map. Well, you may be wrong. Let's look at a different location of Catanduanes on the next.

\subsubsection{Flooding Simulation: 10-meter water level rise in San Andres and Virac}

Flooding in urban areas certainly exact a higher toll in terms of lives, property, displacement, and other problems (Figure 20).

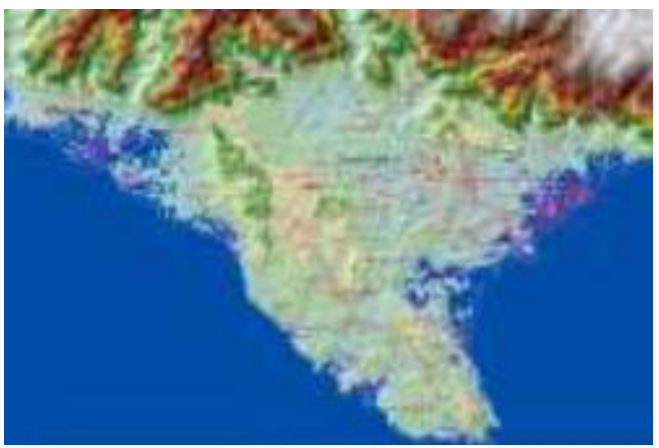

Figure 20 Flooding simulation-10 meter water level rise in San Andreas and Virac

Economic assessment of devastation could run into millions or even billions of pesos. So what are we going to do next? You may think flooding could never occur this high? How sure are you? The 2011 Tohoku earthquake and tsunami in Japan killed 16,000 people and the economic cost of devastation was estimated at US\$235 billion according to the World Bank. The 2004 


\section{Journal of Marine technology and Environment Year 2021, Vol.I}

South Asian earthquake and tsunami killed over 230,000 people from Sri Lanka, Maldives, India, Indonesia, and Thailand. We are lucky (at least for the time being). When are we going to end procrastination? There's no doubt that coastal barangays are most vulnerable to this kind of disaster. GIS certainly can help in planning and implementation of disaster prevention and mitigation programs.

\subsection{Use of GIS for bird conservation}

Let's talk something less scary.The use of GIS for Bird concervation. The illustration shows the point locations of bird sightings in the Canticol and Mt. Hilong-hilong area of Agusan del Norte province (Figure 21).

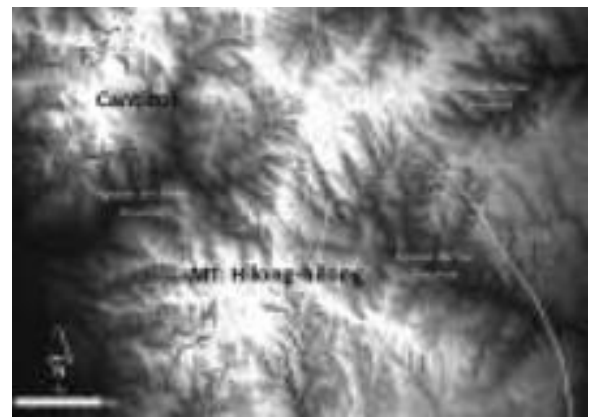

Figure 21 GIS for bird conservation

Although the sightings were of different bird species, the points are all colored black for the black-and-white illustration. In GIS, the points called GPS, which contain latitude-longitude coordinates of birds can be overlaid on a digital elevation map as above. The relative location of the sighting points with each other and with the terrain are shown. Using the scale bar as shown, one can deduce the relative distances of the points and their distance to the provincial boundaries. The information of bird sightings can be used in studies such as bird conservation planning and protected area development.

\subsection{Use of GIS fornavigation and marine resource management}

The map is a hillshade or relief map of Catanduanes overlayed on a bathymetry layer (Figure 22).

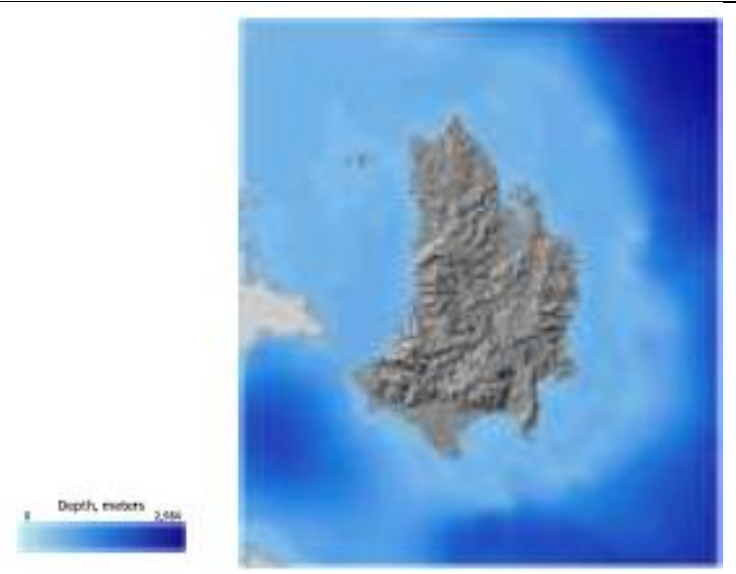

Figure 22 GIS for navigation and resource management

Note the graduated blue color and depth in meters. Catanduanes is closer to the northern vertex of the northsouth elongated Philippine Trench along the eastern coast of the Philippines. The deepest point is $10 \mathrm{~km}$. Research on navigation and coastal resource management entails, among other things, conducting GIS-based bathymetric mapping of the coastal waters of the island. Existing bathymetric data is a rough $1-\mathrm{km}$ resolution and can be downloaded free from the General Bathymetric Chart of the Oceans (GEBCO). The processed result is show in the illustration in front of you. This resolution can do location approximations to do studies, such as marine protected area delineation; spatial analysis of coastal marine life; bathymetry of harbors and approaches; etc. However, higher-resolution bathymetric map is needed for greater detail and clearer representation of the undersea terrain, and thus for better analysis of study results. There are paper nautical charts (old, about 50 years old) of the Philippines produced by the U.S. National Imagery and Mapping Agency (NIMA) [now called National Geospatial-Intelligence Agency (NGA)] containing depth sounding values that could be georeferenced, digitized, converted to point GIS vector files, and mapped as in the illustration above. Please see list of nautical charts at http://www.charts.noaa.gov/NGAViewer/nga9.pdf [5].

Unfortunately, the nautical chart for Catanduanes (NGA Chart 91040) is unavailable for download or viewing from the site. A smaller scale is available for viewing: NGA Chart 91030 at 398,000 scales. Again, these points have to be "oceanfloor-truthed" using recent and detailed bathymetric mapping of the area of interest in order to validate the depth data to be used for research. On the other hand, coastal resource management studies need higher-resolution satellite or other remotely-sensed multispectral imagery to assess the distribution and health of coastal vegetation. Temporal changes of coastal vegetation can be examined from older multispectral imageries and compared with 
the more recent ones. These entails image analysis on a GIS software in order to assess other related information such as reduction (or increase) in vegetative (or urban) land cover.

\subsection{Depth Contours and Labels (Depth Values)}

Here's a similar rendition of sea depth. Vector contour lines were created based on GEBCO 1-km resolution bathymetric grid map and overlayed on the raster bathymetry from the same raw data (Figure 23). These are approximate contour lines and depth values that need to be validated by a more accurate bathymetric data collection and mapping method.

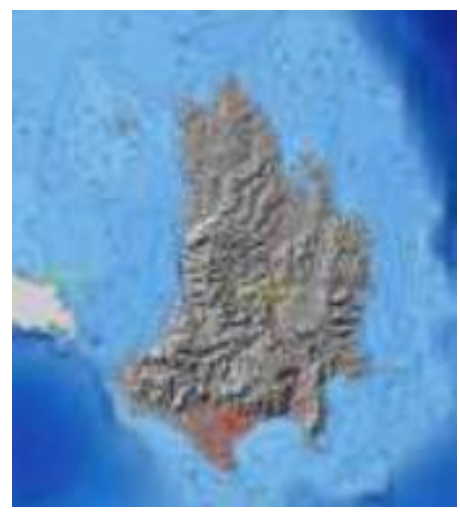

Figure 23 Depth values

Depth labeling of contour lines definitely adds value to the data for viewer. Note that the illustration is an overlay of 5 GIS datasets or layers. Starting from the bottom - Bathymetric Map, Provincial Map of the Philippines (only portion of Camarines Sur is shown; Catanduanes provincial map is also covered by elevation map), Digital Elevation Map of Catanduanes, Contour Lines, and Roads). Any combination of these or other GIS data layers can be used in navigational and coastal environmental research.

With labeling of contours, water depths around the islands are known [11]. Note that the contour lines are drawn at 20-m interval. Widely spaced contour lines suggest gradual depth. Farther from the coasts most notably $15 \mathrm{~km}$ to the northeast and also southwest, depth suddenly

drops like a ravine, as can be seen by the closely spaced contour lines.

\subsection{A view from Google Earth}

What's the difference between Google Earth image and Landsat imagery? Google Earth nowadays presents stunning high resolution true-color pictures of many parts of the country (Figure 24). But the picture is hardly suitable for image analysis.

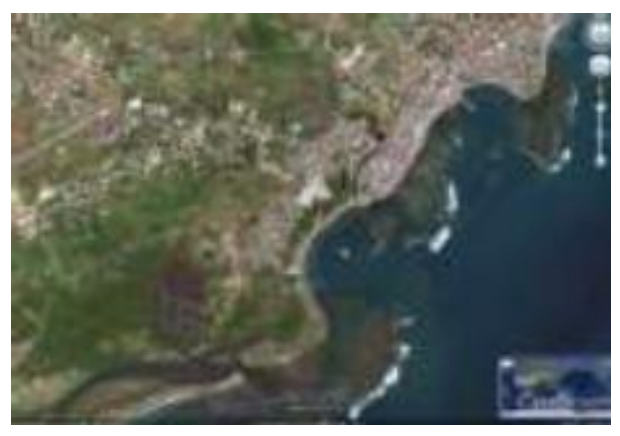

Figure 24 A view from Google Earth

Landsat imagery or multispectral imagery consists of several bands that allow manipulation of the bands by the image analyst to emphasize visual clarity of events such as floods, landslides, forest fires, diseased vegetation, etc. Landsat imagery is available for free at low resolution (30 meters or more). High-resolution imagery (e.g. 10 meters or less) are expensive, about 1 US dollar per sq.km. Points, lines, and polygons can be traced on the imagery, saved as KML file, and converted to GIS files. In contrast, GIS files can be converted to KML files and overlaid in Google Earth. The image itself can be "screenshot", geo-referenced, and used as an overlay on the GIS display.

However, be warned that there may be copyright restrictions regarding this.

\section{CONCLUDING REMARKS}

It can be surmised that GIS is a powerful innovative tool for analyzing the data. It provides answers to the following point of interest like: What's happening inside a certain location? How to prepare for something that will occur within a certain radius or distance What to expect from nearby after finding out what's occurring within a certain radius or distance. Behind the beautiful maps are stories. So what do these maps convey and how do they challenge the analyst, aside from their esthetic value? Using GIS, the beautiful maps produced provides better visualization of project process; easier manipulation of data layers, greater insights on the phenomenon involved and resulting scenario; critical analysis of the scenario and enhanced intelligent decision making to challenges related to the socio-economic development and environmental sustainability of Catanduanes. Hence how should GIS comes into the BIONE3 equation

$$
\text { "water+biodiversity=food+life"? }
$$


GIS should therefore come into the equation as an emphatic exclamation point (GIS!), because indeed GIS is a unique positive catalyzer.

\section{"water+biodiversity $=$ food+life"}

Using GIS to confront real-world problems can lead to intelligent and informed decisions concerning management of environment and natural resources resulting in sustenance of the present and future generations of Catanduanes. This belief must be validated by the Province of Catanduanes by applying GIS in its various data sets to be convinced that the benefits of GIS presented on this paper are real [10], [11].

\section{RECOMMENDED ACTIONS}

For the research, extension services and development of the Province of Catanduanes, this would still be dependent on the quality of its human resources thru GIS capability building for the Catanduanes State Colleges and Catanduanes researchers and planners .

Hence the following actions are recommended. Conduct GIS Training and Workshops; (Use free GIS software to promote GIS knowledge dissemination: Several good ones available, e.g. MapWindow GIS, Quantum GIS, SAGA GIS, DIVA GIS, etc; Invite a trainer that understands local needs and challenges, has a multidisciplinary background, and is open to posttraining questions; Use local data samples during the training to make it as an on-job-problem solving exercise; Install Internet connection if available; if none, that's fine; training can be done without Internet; Bring a capable laptop or desktop computer (at least 2 Gig memory and $100 \mathrm{MB}$ hard drive capacity) );

Initiate and participate in GIS conferences, meetings, lectures, etc; (Network and share knowledge with other GIS enthusiasts like you; Conduct GIS conferences, meetings, lectures, etc. Start in-house, then do local, provincial, regional, etc.);

Apply GIS to your workplace decision-making whenever possible (Learning and applying GIS can be daunting at first, but once you learn to do it, the next challenges become far easier ).

Start a simple GIS-based research project; Collaborate and consult with like-minded GIS persons within CSC or Provincial Capitol. "Two heads are better than one." Call or email the Trainer if you need advice!; Include GIS goals in your Strategic Development Plan to institutionalize GIS and to justify budget allocations for future GIS-based projects and activities; Detail specific GIS-based activities , Start a GIS newsletter; Make a webpage for GIS-based project within the institution's website;

Build a central GIS database for the province; (Collaborate in GIS data buildup to avoid data duplication efforts, share costs in data buildup, thus minimize overall cost); and

Seek collaborations!You may insert acknowledgements in the paper if necessary before the references section.

\section{REFERENCES}

[1] Google earth of Catanduanes Province, Taken 2012.

[2] Catanduanes | Explore the Island of Catanduanes retrieved on 10th January 2015 at

http://www.catanduanes.gov.ph/vision andmission.html

[3] Catanduanes State Colleges - About CSC retrieve on 10th January 2015 at

http://www.csc.edu.ph/about.htm

[4] Geographic Information Systems as an Integrating Technology retrieved on $10^{\text {th }}$ January 2015 at http://www.colorado.edu/geography/gcraft/notes/intro/in tro.html.

[5] nga9.pdf (application/pdf. Object) retrieve on 10th January 2015 at

http://www.charts.noaa.gov/NGAViewer/nga9.pdf

[6] Overview | Geographic Information Systems retrieved on $10^{\text {th }}$ January 2015 at

http://www.gis.com/content/top-five-benefits-gis.

[7] PhilGIS (Philippine GIS Data Clearinghouse) retrieve on 17 Feb 2012 at www.philgis.org

[8] Esri Industries | GIS Mapping Solutions for Industry retrieved on $10^{\text {th }}$ January 2015 at

www.esri.com/industries.html

[9] Google Earth view of the Catanduanes State Colleges campus, Virac Campus, Taken 2012

[10] Dr Alejandro Tongco, Dr Jimmy Masagca Exchanged email communications with GIS Specialist (al.tongco@okstate.edu;(pacifictechjtm@yahoo.com )

[11] LEMENKOVA POLINA, R scripting libraries for comparative analysis of the correlation methods to identify factors affecting Mariana trench formation, Jounal of marine Technology and Environment, pp 3544, vol 2, 2018. 